\title{
PVA Microporous Hydrospheres/Doxorubicin Hydrochloride
}

National Cancer Institute

\section{Source}

National Cancer Institute. PVA Microporous Hydrospheres/Doxorubicin Hydrochloride.

NCI Thesaurus. Code C71149.

An embolic material composed of microspheres of polyvinyl alcohol (PVA) polymers loaded with doxorubicin hydrochloride with antineoplastic activity. Doxorubicin hydrochloride-loaded microspheres may be used as a drug delivery vehicle during embolization of tumor vasculature. Doxorubicin intercalates DNA, interferes with catalytic activity of topoisomerase II, and causes DNA adducts and other DNA damage, resulting in tumor cell growth inhibition and apoptosis. When used in tumor vasculature embolization, this preparation may provide more tumor-specific treatment with doxorubicin compared to the systemic administration of doxorubicin, thereby reducing the systemic toxicity of doxorubicin. 